\title{
Immunonutrition: a South African perspective
}

\author{
Prins A, B Diet, MNutr \\ Little Company of Mary Medical Centre, Groenkloof, Pretoria \\ Visser J, BSc Diet, MNutr \\ Division of Human Nutrition, Faculty of Medicine and Health Sciences, Stellenbosch University \\ Correspondence to: Arina Prins, e-mail: arina.p@internists.co.za \\ Keywords: immunonutrition, nutrition therapy, pharmaconutrition, enteral feeding, parenteral feeding
}

This article was prepared by SASPEN for the Critical 4 Africa Congress 2012, held at Sun City from 29 August - 2 September 2012 and was made possible by an educational grant from Nestlé: Nutrition Institute Africa (NNIA).

\section{Abstract}

Clinical nutrition has evolved from providing nutrients to meet the patient's needs to nutrition therapy that additionally aims to provide specific nutrients, or combinations thereof, which can reduce infection and improve outcomes in critically ill patients. The value of immunonutrition in the management of critically ill, preoperative and postoperative patients is now acknowledged by many healthcare practitioners. Amid the demonstration of clinical and economic benefit in defined conditions, South African practitioners should aim to translate current knowledge to best practice in order to optimise nutrition therapy and ultimately clinical outcome in critically ill patients. For the future, a paradigm shift to pharmaconutrition has been suggested. This practice dissociates the administration of key single nutrients, in the form of requirementbased parenteral or enteral nutrition, from the delivery of pharmaconutrients in the full effective pharmacological dose, as evaluated in large, well-designed trials, in order to achieve therapeutic effects. This has been evaluated in large, well designed trials. The purpose of this review is not to provide an exhaustive overview of the available literature on immunonutrition, but rather to highlight key and recent significant studies, with a focus on energy and protein, glutamine, arginine, omega-3 fatty acids and micronutrients, and relate them to the South African context. Finally, the bigger picture should always be borne in mind, within the settings of the complexity of the acute phase response and the heterogeneity of the critical care population. As the evidence base evolves, the definition of optimal nutrition therapy should include all relevant components in the right mix, at the right time, to the right patients, to ensure optimal clinical benefit and outcome.

\section{Introduction}

Over the last two decades, clinical nutrition has evolved from nutritional support that is intended to meet the patient's needs only (denoting a passive role), to nutrition therapy that is selected according to the patient's disease or medical condition. Currently, there is renewed interest in nutritional therapy in critical illness, particularly in the areas of immunonutrition and pharmaconutrition (or nutritional pharmacology). ${ }^{1}$ It is now known that nutrition is much more than just delivering basic substrates or nutrients that play a role in providing a fuel source for basic metabolism and cell growth, but that there are specific nutrients, or combinations thereof, that can reduce the risk of infection and improve outcomes in critically ill patients. ${ }^{2}$

Immunonutrition has been described as the ability to modulate the inflammatory or immune response by nutrients or a specific food item that is fed in amounts above what is normally consumed through the diet alone. ${ }^{3,4}$ Furthermore, some nutrients, when given in higher doses, appear to serve as pharmacological agents. In the latter context, these pharmaconutrients may positively or negatively alter clinical outcomes in a manner that is not dissimilar to the way in which any other pharmacological agent functions. ${ }^{1,5,6}$

The earliest scientific evidence that implicates the role of nutrition in immune function is probably the description of thymic atrophy that was provided by Menkel in $1810 .^{7}$ The birth of nutritional immunology (1800s) and the vitamin era (1900s) improved our understanding of the impact of nutritional deficiencies on the immune system. ${ }^{7}$ Some of the pioneering work in immunonutrition was carried out by Alexander at the Shriners Burns Institute. His research led to the formulation of the Shriners' burn formula, an enteral (EN) feeding solution that contained arginine, $\omega-3$ fatty acids (FAs), and vitamins A, C and zinc. ${ }^{8}$ This formula resulted in reduced length of stay and reduced wound infections. ${ }^{9}$ Thus immunonutrition is not a new concept as it is often regarded, but rather the application thereof to new clinical settings.

The purpose of this article is not to provide an exhaustive review of the available literature on immunonutrition, but rather to highlight key and recent significant studies and relate them to the South African context. One of the restricting factors in providing state- 
of-the-art health care in South African is limited available finances. Often immunonutrition is perceived to be expensive when compared with standard enteral (EN) and parenteral (PN) products. Healthcare providers need to be more aware of the evidence base that supports the benefits of immunonutrition in defined populations, and that such an approach could ultimately result in cost saving, when prescribed correctly.

\section{The critical care patient population}

The population in the intensive care unit (ICU) is heterogeneous in nature. This diverse population suffers severe physiological stress or organ failure with varying degrees of acute phase response, insulin resistance and hyperglycaemia, protein loss, impaired gut function and immune system alterations. It has been suggested that the metabolic response after injury should be divided into three distinct phenotypes: the ischaemia-reperfusion phenotype, leucocyte phenotype and angiogenic phenotype. ${ }^{10}$ This may help to determine the best nutrition therapy for patients in a specific category. Furthermore, it has been consistently documented that approximately $15-70 \%$ of patients are undernourished or malnourished on admission to hospital, ${ }^{11-16}$ which further complicates the provision of optimal nutrition therapy. Against this heterogeneity, while the provision of nutrients to meet requirements remains of paramount importance, it might be considered simplistic that the "one nutrition therapy regimen will fit all" approach can provide optimal therapeutic support.

\section{What is to be achieved?}

In part, the goal of the nutrition therapy dietitian or practitioner could be described as supplying the best possible nutrition therapy to the patient to aid the recovery process, prevent complications and discharge a functional patient home. This encompasses screening and assessing, as well as supplying the correct amount and mix of nutrients to support and modulate the acute phase response and immune system, and maintain and improve nutritional status. Due to high demand and cost of care, the overall objective remains minimising the duration and costs of hospitalisation, while still trying to provide optimal care. This raises the question whether or not these goals are mutually exclusive since immunonutrition is deemed to be expensive.

By preventing and managing the complications of malnutrition, nutrition therapy dietitians contribute significantly to lowering care costs. Protein-energy malnutrition (PEM) has been shown to be an independent risk factor for morbidity and mortality. PEM is associated with a significantly higher risk of complications, such as infection, increased mortality, increased length of stay in hospital and ICU, decreased quality of life and poorer prognosis, all of which have been shown to increase care costs. ${ }^{11,16-19}$ In this regard, despite the respective limitations of the reported studies, the consistency of the reported findings (Table I) may be more important than the actual costs, which are country-dependent. In addition, malnutrition is also associated with impaired cell-mediated immunity with changes in peripheral lymphocyte subsets, as well as increased cortisol levels and T-helper 1 to T-helper 2 cytokine shift. ${ }^{20}$ Furthermore, unplanned readmission of medical patients has been shown to be associated with chronic disease, depressive symptoms and underweight. ${ }^{21}$

\section{The South African scenario: hospital malnutrition}

The broader incidence of adult malnutrition in South African hospitals is largely unknown. Only a few studies are available in the published literature to date (Table II). The authors are aware of ongoing studies that should provide further crucial information once such information becomes available. The study populations vary and range from groups with high incidences of tuberculosis and human immunodeficiency virus (HIV)/acquired immune deficiency syndrome (AIDS), to groups who present with lifestyle diseases. Nevertheless, the high prevalence of malnutrition is consistent and the evaluated nutritional status parameters are known to be associated with higher care costs.

Table I: Costs associated with malnutrition

\begin{tabular}{|c|c|}
\hline Study & Outcomes \\
\hline Reilly et al, $1988^{22}$ & $\begin{array}{l}\text { Well-nourished and no complications: } \$ 2968 \text { (hospital stay) } \\
\text { Malnourished and complications: } \$ 12683 \text { (hospital stay) }\end{array}$ \\
\hline Chima et al, $1997^{23}$ & $\begin{array}{l}\text { Not at risk of malnutrition: } \$ 4563 \pm 3702 \text { (hospital stay) } \\
\text { At risk of malnutrition: } \$ 6196 \pm 4585 \text { (hospital stay) }\end{array}$ \\
\hline Desport et al, $1999^{24}$ & $\begin{array}{l}\text { Mean daily hospital cost per well-nourished patient: } \$ 138 \\
\text { Mean daily hospital cost per malnourished patient: } \$ 228\end{array}$ \\
\hline Braunschweig et al, $2000^{25}$ & $\begin{array}{l}\text { Normally nourished at admission and discharge: } \$ 28631 \pm 1835 \\
\text { Patients who declined nutritionally, regardless of nutritional status at admission: } \$ 45762 \pm 4021\end{array}$ \\
\hline 0'Flynn et al, $2005^{26}$ & Malnutrition costs the NHS in excess of $£ 266$ million annually through longer length of stay, readmissions and treatment costs \\
\hline CEPTON study, $2007^{27}$ & Direct costs of under-nutrition and malnutrition amount to $€ 9$ billion/year in Germany \\
\hline Euro00PS study, $2008^{28}$ & $\begin{array}{l}\text { NRS "at risk": } \uparrow \text { mortality (12\%); } \uparrow \text { length of stay in hospital (9 days); } \uparrow \text { complications }(30.6 \%) ; \uparrow \text { cost } \\
\text { NRS "not at risk": } \downarrow \text { mortality (1\%); } \downarrow \text { length of stay is hospital (6 days); } \downarrow \text { complications }(11.3 \%) ; \downarrow \text { cost }\end{array}$ \\
\hline PREDYCES study, $2009^{29}$ & $\begin{array}{l}\text { Patients at risk on admission: } € 8207 \\
\text { Patients who were not at risk on admission: } € 6798 \\
\text { Patients who developed malnutrition in hospital: } € 12237 \\
\text { Patients who did not develop malnutrition in hospital: } € 6408\end{array}$ \\
\hline
\end{tabular}

NHS: National Health Service, NRS: nutritional risk screening (NRS-2002) 
Table II: Incidence of adult malnutrition in South African hospitals

\begin{tabular}{|l|l|}
\hline Area, year & Description of malnutrition \\
\hline Zululand, $1983^{30}$ & $\begin{array}{l}\text { Medical patients: } \\
93 \% \text { of male and } 72 \% \text { of female patients: Triceps } \\
\text { skinfold thicknesses }<60 \% \text { of normal } \\
\text { One third of patients: clinically marasmic }\end{array}$ \\
\hline Durban, $1983^{31}$ & $\begin{array}{l}\text { Hospitalised urban black patients: } \\
\text { Significantly reduced fat stores: } 82 \% \text { males }\end{array}$ \\
\hline Cape Town, 1984 & $\begin{array}{l}\text { Medical and surgical patients: } \\
\text { Significant body weight depletion: } 20 \% \text { of patients }\end{array}$ \\
& $\begin{array}{l}\text { Significant fat depletion: } 30 \% \text { of patients } \\
\text { Significant muscle depletion: } 15 \% \text { of patients }\end{array}$ \\
\hline Cape Town, $1988^{33}$ & $\begin{array}{l}\text { Tuberculosis hospital: } \\
\text { Decreased body weight: } 32.3 \% \text { of patients } \\
\text { Fat depletion: } 78.8 \% \text { of patients } \\
\text { Muscle depletion: } 37 \% \text { of patients }\end{array}$ \\
\hline Cape Town, $1997^{34}$ & $\begin{array}{l}\text { Medical patients: } \\
\text { Severe malnutrition: } 17 \% \\
\text { Subclinical malnutrition: } 77 \%\end{array}$ \\
\hline Eastern Cape, $2011^{35}$ & $\begin{array}{l}\text { Burn patients: } \\
46.3 \% \text { malnourished at admission }\end{array}$ \\
\hline
\end{tabular}

\section{Infection and sepsis}

Approximately $5-10 \%$ of patients who are admitted to acute care hospitals acquire one of more infection, affecting two million patients each year, and resulting in approximately 90000 deaths annually in the USA. This adds an estimated $\$ 4.5-5.7$ billion per year to the costs of patient care. ${ }^{36}$

Sepsis, septic shock and the adverse sequelae of the systemic inflammatory response syndrome (SIRS) have been shown to be the $10 \mathrm{th}^{37}-13 \mathrm{th}^{38}$ most common cause of death in the USA and the second most common cause of death in non-coronary ICUs. ${ }^{37}$ Sepsis is often lethal. It is suggested that the mortality rate is between $20-50 \%$ in severely ill patients ${ }^{37}$ or $8-90 \% .^{38}$ Only $10 \%$ of deaths were reported to be related to underlying disease, while $25 \%$ were attributable to bacteraemia. ${ }^{38}$

Costs that relate to care of a patient with sepsis have been described to be as much as $\$ 50000$ per patient, resulting in an annual burden of approximately $\$ 17$ billion. ${ }^{37}$ There are approximately 400000 500000 septic episodes annually in the USA. ${ }^{38}$ The Centers for Disease Control and Prevention (CDC) reported a 139\% increase in the incidence of sepsis over the last 10 years. This occurred despite advances in knowledge and technological support. ${ }^{38}$ Sepsis accounts for $\$ 5-10$ billion of the annual healthcare costs in the USA ${ }^{38}$ and is reported to be the cause of $10 \%$ of ICU stays. ${ }^{37}$

Although similar statistics are not available in South Africa, it is consistently documented that patients with infectious complications or sepsis have a longer length of stay and require second- and thirdgeneration antibiotics, both of which have major cost implications. It is reasonable to conclude that if nutrition can play a role in the management or prevention of infection and sepsis, it will ultimately benefit the patient and reduce care costs.

\section{Immunonutrition and pharmaconutrition}

\section{Nutrition and the immune system}

Nutrition and the immune system interact on various levels and four such stages of interaction have been described. ${ }^{7}$ Stages I (complete nutrition) and II (optimising macronutrients and micronutrients) are the so-called "passive" stages which aim to supply the immune system with essential nutrients. Stages III (active modulation of the immune system) and IV (personalised nutrition) involve modification of the immune response through immune response modifiers (IRMs) that primarily target the pathogen-associated molecular patterns (PAMP) expressed by microbial pathogen receptors in the gut and involve more active approaches in modulating immune status. ${ }^{7}$

\section{Immunonutrition and pharmaconutrition in critical illness}

In ancient cultures, very few patients survived 72 hours following severe illness or trauma. In the modern world, ambulances, ventilation, medication and nutrition therapy enable patients to survive serious insults and trauma that might have proved fatal. Today, some of the major challenges are sepsis and containment of the inflammatory response. Despite following strict protocols and procedures, including timely screening and assessment, early nutrition therapy and meeting nutrient requirements, there is a high incidence of complications such as infections and multi-organ failure (MOF), as well as malnutrition. The nutrition therapy practitioner is left with the question whether it is possible to influence the outcome in favour of positive clinical outcomes. Possible proposed solutions in the literature, and which are founded on a growing evidence base, include the use of nutrients to modulate the acute phase and immune response, to prevent oxidative damage, to ensure glycaemic control and to provide probiotics to alter the gut environment, as well as sufficient energy and protein. Probiotics are used to alter the gut environment. Nutrients are also used to provide sufficient energy and protein.

The targets of pharmaconutrients are the immune system, muscles and intestines. The expected benefits include preservation of lean body mass, decreased intestinal permeability, decreased proinflammatory response/SIRS, decreased nosocomial infections, shorter length of stay, decreased mortality and a decrease in care costs. Various nutrients have been suggested or have been shown to play a role as pharmaconutrients, including zinc, selenium, vitamin $\mathrm{E}$, vitamin $\mathrm{C}$, glutamine, arginine, ornithine- $\alpha$-ketogluterate, fibre/short-chain FAs (SCFAs), prebiotics, probiotics and synbiotics, as well as energy and protein., 49

Just as antibiotics are organism-specific, all pharmaconutrients may not be beneficial in all critically ill patient populations at a given time. The effectiveness of a pharmaconutrient may be dependent on the stage or category of the acute phase response. For instance, the septic patient is in a hyperinflammatory state with SIRS predominance, with late predominance of the compensatory antiinflammatory response syndrome (CARS) resulting in a second round of infections, MOF and death. Typically, trauma and surgical patients display CARS predominance early on. Consequent infections result in sepsis and death. Therefore, it is clear that different nutrients will have different advantages and modulatory effects in these two states. $^{20,40-42}$ 


\section{Energy and protein}

Although energy and protein are not commonly described as pharmaconutrients, it is well known that protein and energy insufficiency results in malnutrition which is associated with an impaired immune response and impaired wound healing, both of which are in turn associated with infections. ${ }^{43}$ In the South African scenario, where finances are often limited, it is imperative to first provide the patient with basic nutrition support that meets the patient's requirements. This includes meeting energy and protein requirements through EN, PN or both routes, early EN nutrition to support the gut-associated lymphoid tissue (GALT), mucosaassociated lymphoid tissue (MALT) and modulate cytokines, and ultimately optimal feeding. Although this approach will not necessarily modulate the immune response, it will at least support the immune system. Various other nutrients have been also shown to play a role in the immune system, including vitamins, minerals and trace elements. Thus, meeting basic requirements is a prerequisite for a functional immune system. ${ }^{7}$

Despite increased awareness and efforts, very few ICUs worldwide successfully execute the basics in terms of nutrition support. In a study which included 259 ICUs worldwide ( $n=5497$ ventilated patients), it was shown that when compared with medical patients, surgical patients were less likely to receive EN ( $54.6 \%$ vs. $77.8 \%)$ and more likely to receive PN $(13.9 \%$ vs. $4.4 \%)$ ( $p$-value $<0.0001)$.
In patients in whom EN was initiated, on average, surgical patients started EN 21 hours later (57.8 vs. 36.8 hours, p-value $<0.0001$ ) and received less of their prescribed energy from EN (33.4\% vs. $49.6 \%, p$-value $<0.0001)$ or from all nutrition sources $(45.8 \%$ vs. $56.1 \%$, $p$-value $<0.0001$ ) than medical patients. ${ }^{44}$ Therefore, basic principles need to be established and cemented to be able to successfully add immunonutrition and pharmaconutrition concepts when supporting such patients.

The source of protein that is used in an EN formula may also impact on immune function. Whey protein is high in branched chain amino acids, particularly leucine, which is known to play various roles, ranging from being a substrate for protein synthesis, to a modulator of insulin signaling. In addition, whey protein is high in cysteine which is the limiting amino acid for glutathione synthesis and is necessary for antioxidant defenses. Whey, a "fast" protein, preferentially stimulates protein synthesis which potentially makes it an excellent source of amino acids in critically ill patients. ${ }^{45}$ Gastric emptying of whey-based formula is faster than similar casein-based formula ${ }^{46}$ and may be beneficial in critically patients with motility disorders. A comparison of equal volumes of wheybased formula that had different energy densities and osmolalities indicated that they emptied at a comparable rate. This can improve nutrient delivery to patients with volume intolerance..$^{46}$ Preclinical studies reported that whey protein also facilitated protein synthesis, decreased inflammation, had antioxidant effects and reduced gut- 
Table III: Glutamine for specific patient populations: clinical practice recommendations $s^{53,56,69}$

\begin{tabular}{|l|c|c|c|}
\hline Patient population & CCCPG & ASPEN/SCCM & ESPEN \\
\hline General & No recommendation & Possible benefit (B) & No recommendation \\
\hline Elective and major surgery & No recommendation & No recommendation & No recommendation \\
\hline Trauma & Possible benefit & Possible benefit (B) & ${\text { Benefit }(A)^{* *}}^{*}$ \\
\hline Sepsis & No recommendation & No recommendation & No recommendation \\
\hline Burns & Possible benefit & Possible benefit (B) & Benefit (A) $^{*}$ \\
\hline ALI/ARDS & No recommendation & No recommendation & No recommendation \\
\hline
\end{tabular}

ALl: acute lung injury, ARDS: acute respiratory distress syndrome, ASPEN: American Society for Parenteral and Enteral Nutrition, CCCPG: Canadian Critical Care Practice Guidelines, ESPEN: European Society for Clinical Nutrition and Metabolism, SCCM: Society of Critical Care Medicine

Grading (A, B) based on level of evidence: American Society for Parenteral and Enteral Nutrition/Society of Critical Care Medicine $\mathrm{e}^{53}$ and European Society for Clinical Nutrition and Metabolism ${ }^{69} \mathrm{grading}$ *ASPEN: Grade B recommendation: supported by one level I [large, randomised trials with clear-cut results, low risk of false-positive (alpha) error or false-negative (beta) error] investigation

**ESPEN: Grade A recommendation: (la) meta-analysis of randomised controlled trials, or (lb) at least one randomised controlled trial

reperfusion injury. ${ }^{47} \mathrm{~A}$ double-blind randomised controlled trial (RCT) compared early EN with a formula containing whey with standard EN (containing casein as the protein source) in ischaemic stroke patients, and reported that whey may decrease inflammation and increase antioxidant defenses. ${ }^{48}$

Small peptide EN formulation may also be beneficial as a number of studies have reported that at a physiological level these formulations are easier to absorb over the gut lumen, result in less feeding intolerance and increase protein synthesis at the visceral level through increased nitrogen retention. Preclinical studies have shown a greater increase in glucagon which may have a positive trophic effect on the intestinal mucosa. Animal studies have also shown that peptide diets have higher levels of nitrogen retention, higher rates of weight gain, higher rates of tissue repair and a positive trophic effect on the small bowel mucosa, compared to free amino acid formulations. ${ }^{47}$

However, more human data is necessary to substantiate the claims for both whey protein and small peptides based protein sources and to strengthen the evidence-base in clinical practice. It should nevertheless be noted that these substrates are currently much cheaper than pharmaconutrients, are readily available in the South African market, and should thus at least be considered in the treatment of critically ill patients in the local context.

\section{Glutamine (cell-protective nutrients)}

Glutamine is now considered by many investigators to be "conditionally essential" in critical illness. ${ }^{49,50}$ Deficiency can develop within 24 hours in this group of patients. It is the most abundant free amino acid in the body, but stores are rapidly depleted during injury or critical illness. Deficiency states are described in patients with trauma, sepsis, surgery and burns. ${ }^{8,50,51}$ Glutamine serves as a metabolic substrate for immune cells and enterocytes, supporting barrier and immune function. ${ }^{50}$ It may also serve as a vital cellsignalling molecule in states of illness and injury. ${ }^{52}$ In this regard, glutamine has been shown to regulate the expression of many genes that relate to metabolism, cell repair and defense, signal transduction and activation of intracellular signalling pathways. ${ }^{52}$ Glutamine release could further serve as a "stress signal" to the organism to turn on genes that are vital to cellular protection and immune regulation. ${ }^{50}$ An example of the latter is glutamine's potential key role in enhancing the synthesis of heat-shock proteins (HSPs), which are essential to cellular recovery following injury, and for protection against organ failure. .,50 $^{2}$

On the balance of the available evidence, glutamine supplementation in critically ill patients is currently recommended by the American Society for Parenteral and Enteral Nutrition (ASPEN)/Society of Critical Care Medicine (SCCM), ${ }^{53}$ European Society for Parenteral and Enteral Nutrition (ESPEN) ${ }^{54}$ and the 2009 Canadian Practice Guidelines. ${ }^{55,56}$ A 2009 systematic review demonstrated that glutamine supplementation of total PN (TPN) reduced mortality by $29 \%$. All EN and PN studies showed a $25 \%$ reduction in mortality. ${ }^{56}$ In line with these findings, a recent Scandinavian study $(n=413)$ also found a reduction in mortality with intravenous (IV) glutamine. ${ }^{57}$ However, the Scottish Intensive care Glutamine or seleNium Evaluative Trial (SIGNET) in 10 centres in Scotland ( $n=502$ ) showed no significant effect of glutamine supplementation of TPN on mortality or infectious complications. ${ }^{58}$ The lack of effect of glutamine in the Scottish trial has been attributed to various factors, including the low dose of glutamine used (20 g/day), the short period of administration (four to five days) and late implementation. Trials with $>0.3 \mathrm{~g} / \mathrm{kg}$ have been shown to have better outcomes. The best results were obtained using $0.5 \mathrm{~g} / \mathrm{kg}$ of IV glutamine. ${ }^{59}$ The available literature suggests that glutamine needs to be administered early since deficiency can develop within 24 hours. The no-effect of IV glutamine on plasma glutathione $e^{60}$ or the innate immune system ${ }^{61}$ may indicate that glutamine exerts its beneficial effects via mechanisms other than the immune system, such as HSP induction.

EN supplementation of glutamine has a significant beneficial effect on immunity, as shown in burn patients. In these patients, $26 \mathrm{~g}$ enterally supplied glutamine resulted in three times less frequent positive blood cultures. ${ }^{62}$ Fourteen days of glutamine supplementation via the EN route $(0.5 \mathrm{~g} / \mathrm{kg} /$ day) significantly increased serum glutamine levels, ${ }^{63,64}$ as well as plasma pre-albumin and transferrin levels. ${ }^{64}$ In thermal injury, a setting that is associated with suppressed cellular immunity, glutamine supplementation significantly improved various measures of cellular immunity, but had no effect on humoral immunity. ${ }^{63}$ Hospital stay in such patients was significantly reduced in both studies and wound healing was faster. ${ }^{63,64} \mathrm{EN}$ glutamine supplementation in other groups of critically ill patients has been less 
beneficial, possibly due to the low dose administered and ingested for a clinical effect to be documented, as shown by Soquel et al. ${ }^{65}$

Considering the strength of the evidence base, the administration of glutamine in defined critical care settings (Table III) should be standard practice in the South African context. Large, multi-centre RCTs are currently underway which will provide further clarify and better define glutamine requirements in critically ill patients. ${ }^{66-68}$

\section{Arginine (immune-modulating nutrients)}

As the evidence base expanded, the hype surrounding arginine as a pharmaconutrient included initial optimism, followed by severe caution, to having a definite and appropriate place in the critical care setting. Arginine can enhance immune parameters, e.g. lymphocyte function, after trauma and surgery, and has been shown to improve wound healing. ${ }^{70,71}$ On the other hand, very little benefit and perhaps harm has been observed in septic patients. ${ }^{72-74}$ Arginine may enhance the systemic inflammatory response in septic patients. This results in increased mortality. 72,75 This is a clear example that the "one nutrition therapy regimen will fit all" approach is not appropriate in the critical care setting.

Arginine plasma levels have been shown to be significantly reduced in surgical and trauma patients, but not in septic patients. ${ }^{76}$ Arginase levels are only modestly increased in septic patients, as compared to the significant increase that is seen in trauma patients. ${ }^{8,77}$ During sepsis, there is a classic macrophage response and a maximum increase in inducible nitric oxide synthase (iNOS), interleukin (IL)-1 and T-helper cell 1 cytokine proliferation [interferon- $\gamma, \mathrm{IL}-1$, tumour necrosis factor (TNF)]. In trauma, the alternative macrophage response results in significant arginase increase, IL-10 and T-helper 2 cell cytokine proliferation (IL-4 and IL-13) ${ }^{70,78}$ Thus, clinical benefit has not been demonstrated for the use of arginine in septic patients.

Two recent systematic reviews in surgical patients demonstrated a reduction in infectious complications, length of stay and postoperative infections with arginine supplementation. ${ }^{79,80}$ These two reviews reported no harm in surgical patients. The Drover et al systematic review on perioperative supplementation of arginine (it included 35 trials) supports a significant treatment effect of arginine therapy following elective surgery. ${ }^{79}$ Arginine-supplemented diets were associated with considerably reduced overall infectious complications when compared with standard formula in surgical patients [28 trials included; relative risk $(\mathrm{RR})=0.59,95 \%$ confidence interval (Cl), 0.50-0.70, p-value $<0.00001, \mathrm{I}^{2}=26 \%$ )]. Overall hospital length of stay, aggregated across 29 studies, was reduced in surgical patients receiving arginine-supplemented diets when compared with patients receiving standard formula [weighted mean difference $(\mathrm{WMD})=-2.38 ; 95 \% \mathrm{Cl},-3.39$ to $-1.36 ; \mathrm{p}$-value $<0.00001 ; \mathrm{I}^{2}=87 \%$. Arginine-supplemented diets did not have a significant effect on mortality.

Considering the evidence-base, arginine supplementation should be standard practice where safe and appropriate (for surgery and trauma) in the South African context. 


\section{Omega-3 fatty acids (anti-inflammatory nutrients)}

Fish oils decrease the production of pro-inflammatory mediators. ${ }^{81}$ The anti-inflammatory properties occur through three principle mechanisms: displacement of arachidonic acid in cell membranes, prostaglandin E3 and LTB4 production, decreased nuclear factorkappa B (NF-KB) and AP-1 activation. ${ }^{81}$ Omega-3 FAs ( $\omega-3$ FAs) have also been shown to decrease the production of nitric oxide (NO) via downregulation of iNOS protein expression. ${ }^{81,82}$ Although the inclusion of $\omega$-3 FAs in nutrition therapy makes theoretical sense and the potential mechanisms are fairly clear, the data for the implementation of such nutrient therapy in critically ill patients are much less concrete.

Of particular interest in the critically ill patient is the effect of $\omega$-3 FAs on the adult respiratory distress syndrome (ARDS). An EN product that contains fish oils, borage oil and antioxidants is recommended by the Canadian Practice Guidelines 2009 for the treatment of ARDS. ${ }^{55,56}$ Three studies with the said product as active intervention in patients with diagnosed ARDS have shown a reduction in pulmonary neutrophils, an improvement in oxygenation, decreased severity of ARDS, decreased ventilator days, decreased length of stay in ICU and length of stay in hospital and decreased lung cytokine and protein secretion. ${ }^{83-85}$ Despite these positive results, some concerns were raised regarding the studies. These included the fact that the control groups received high-fat formula, some studies did not have an intention-to-treat design and it was difficult to conclude whether it was the fish oil or other constituents in the formula that exerted the reported positive outcomes.

Three recent studies complicated the interpretation of findings even further. A multi-centre study in Brazil (INTERSEPT study, 14 ICUs, $\mathrm{n}=200$ ) used the same product (as described above) for seven days in patients in the early stages of sepsis and with no organ failure.Although there were significant effects on some secondary outcomes such as length of stay in hospital and lenght of stay in ICU (LICU), there was no effect on mortality. ${ }^{86}$ It is important to note that the fish oil-containing product was used for prevention, and not as treatment, and that once more, the other nutrients may also have exerted beneficial effects. No benefit of the same product was found in a RCT in 11 Spanish ICUs $(n=89)$ in patients with a diagnosis of sepsis on admission. ${ }^{87}$ The Early versus delayed Enteral Feeding (EDEN)-OMEGA study investigated whether $\omega-3$ FAs improved ventilator free days. In this multi-centre RCT (44 centres, $n=272$ ) patients received EN supplementation (twice daily) of $\omega$-3 FAs, $\gamma$-linolenic acid and antioxidants compared with an isocaloric control, within 48 hours of developing acute lung injury (ALI). It is important to note that this was administered as a bolus, whereas in the other studies the patients received continuous EN nutrition. The supplementation did not improve the primary endpoint of ventilator-free days or other clinical outcomes in ALI, and the practice may have been harmful. Sixty-day-hospital mortality was $26.6 \%$ in the $\omega-3$ supplemented group vs. $16.3 \%$ in the control group ( $p$-value $=0.054$ ). Adjusted 60 -day mortality was $25.1 \%$ and $17.6 \%$ in the $\omega-3$ and control groups, respectively ( $p$-value $=0.11$ ). The study was terminated early because of futility. ${ }^{8}$ In a phase II RCT in five North American centres $(n=89)$ the addition of fish oil did not reduce the biomarkers of pulmonary or systemic inflammation in ALI. In this case, the fish oil was supplemented as a bolus as a single nutrient $[9.75 \mathrm{~g}$ eicosapentaenoic acid (EPA) and $6.75 \mathrm{~g}$ docosahexanoic acid (DHA) daily]. The researchers concluded that the results did not support the conduct of a larger clinical trial in this population with this particular agent. ${ }^{89}$

Heterogeneity of studies investigating the supplementation of EN fish oils complicates decision-making on the part of the nutrition therapy practitioner and makes the drawing of firm conclusions difficult. Although many of these studies have robust study designs, in many cases the study design, method of administration (bolus vs. continuous) and disease (established ARDS vs. ALI vs. sepsis) differed and single or mixed nutrients were investigated. However, it seems that bolus administration of fish oils is harmful in this group of critically ill patients and should not be practised.

Guidelines with regard to the use of PN lipids differ between the North American and European organisations. ESPEN recommends the use of lipid emulsions as part of TPN, ${ }^{54}$ while ASPEN and the Canadian guidelines recommend TPN without soy-based lipids. . $3,55,56^{5}$ The difference in these guidelines can probably be attributed to the regional availability of lipid sources ( $\omega-3$ containing lipid sources is not yet available in North America). The Canadian Practice Guidelines 2009 further state that there is insufficient evidence to draw a conclusion as to the type of lipid to be used in critically ill patients on TPN.

Four small recent studies using $\omega-3$ FA containing PN had different interventions ( $\omega-3$ FAs as part of PN or supplemented PN $\omega-3$ FAs). Although there was some indication of a reduction in mortality, no effect on infectious complications was documented. ${ }^{90-93} \mathrm{~A}$ significant reduction in procalcitonin levels was found in the study by Khor et al, suggesting that fish oil attenuates the inflammatory process. ${ }^{92}$ A small study $(n=16)$ compared a standard PN lipid emulsion to a lipid emulsion containing $\omega-3$ FAs in patients with ARDS. The fish oil-supplemented PN resulted in a beneficial alteration in lipid mediator profiles, ${ }^{94}$ the clinical significance of which still remains to be confirmed. A third-generation lipid emulsion containing soybean, medium-chain triglyceride, olive and fish oils (SMOFlipid) resulted in favorable FA profiles (a desirable reduction in the $\omega-6 / \omega-3-F A$ ratio $)^{95}$ and retained hepatocellular integrity. ${ }^{96}$ Small trials showed that fish oil- $(\omega-3)$ supplemented PN had anti-inflammatory and hepatoprotective effects in hyperinflammatory disease such as sepsis, ${ }^{97}$ a beneficial effect on $\mathrm{PN}$-associated liver disease, ${ }^{98}$ reduced the Acute Physiology and Chronic Health Evaluation (APACHE) II and Simplified Acute Physiology Score II, as well as procalcitonin in sepsis. ${ }^{92}$ However, clearly larger trials are required to confirm the findings or form the basis for recommendations in practice. A systematic review (six trials were included) concluded that PN lipid emulsions that contain fish oil had no mortality advantage, but significantly reduced infectious complications ( $p$-value $=0.03$ ). There was a trend towards shortening hospital length of stay by 3.06 days (the exclusion of a heterogeneous study showed a significant reduction), and significantly reduced ICU length of stay by 2.07 days. ${ }^{99}$ The authors of the systematic review further concluded 
that although insufficient data precluded a conclusive economic advantage, the possibility of cost reduction existed, ${ }^{99}$ a conclusion that remains to be confirmed in clinical practice.

Considering the current evolving evidence base and available guidelines, $\omega-3$ FAs should be considered to form part of PN lipid emulsions, at least for their effect on lipid profiles and PNassociated liver disease as discussed above, but strengthening of the evidence base is needed to reach firmer conclusions. EN omega-3 FA supplementation [fish-oil derived $\omega$-3 FAs (EPA and $\mathrm{DHA})$, borage oil and antioxidants] administered in the context of an immune-enhancing diet is currently recommended specifically for patients presenting with ALI and ARDS by ASPEN/SCCM (Grade A recommendation), ${ }^{53}$ ESPEN (Grade $B$ recommendation) ${ }^{69}$ and the 2009 Canadian Practice Guidelines. ${ }^{56}$

\section{Micronutrients}

Critical illness is associated with increased production of reactive oxygen species and oxidative stress, and low levels of most micronutrients, with resultant diminished endogenous antioxidant defenses. ${ }^{100}$ The inherent antioxidant potential is overwhelmed in critically ill patients, resulting in cell damage, the SIRS response and increased morbidity and mortality in critically ill patients. ${ }^{81}$ Micronutrient supplementation is thought to be beneficial to critically ill patients by ameliorating oxidative stress and by improving clinical outcomes.
Research on micronutrient supplementation in the critically ill has focused mainly on five micronutrients: selenium, zinc, copper, vitamins $C$ and $E$. Individual studies have investigated the vitamin B group. ${ }^{100}$ The aims of supplementation can be described as provision of basic nutritional support (bearing in mind the increased requirements due to hypermetabolism and wound healing), the prevention and correction of deficiencies and modulation of the APR and immune responses through reinforcement of endogenous antioxidant defenses.

Trials in patients with thermal injury have focused mainly on selenium, zinc and copper, after low blood concentration of these micronutrients had repeatedly been shown in this patient population, as well as the known uniqueness of this group of patients in terms of the extensive cutaneous losses of these micronutrients. ${ }^{101-104}$ Berger et al consistently demonstrated in a series of well controlled trials that trace element supplementation reduces infectious complications in burn patients. Supplementation (IV) of copper 2.5-3.1 mg/day, selenium 315-380 $\mu \mathrm{g} /$ day, and zinc $26.2-31.4 \mathrm{mg} /$ day for eight to 21 days resulted in a significant reduction in the number of infections. This related to a significant reduction of nosocomial pneumonia $(p$-value $<0.001)$ and of ventilator-associated pneumonia $(p$-value $=$ $0.023) .^{105}$ This is in agreement with the authors' previous data which showed that trace element supplementation resulted in a significant reduction in bronchopneumonia infections and consequent shorter hospital length of stay. ${ }^{106}$ Patients receiving $59 \mu \mathrm{mol} \mathrm{Cu}, 4.8 \mu \mathrm{mol}$ 
Table IV: Supplemented antioxidant nutrients, vitamins and trace elements ${ }^{53,54,56}$

\begin{tabular}{l|l|l}
\hline CCCPG & ASPEN/SCCM & ESPEN \\
$\begin{array}{l}\text { Based on three level I, and } 13 \text { level II studies, the } \\
\text { use of supplemental combined vitamins and trace } \\
\text { elements should be considered in critically ill } \\
\text { patients. }\end{array}$ & $\begin{array}{l}\text { Combination of antioxidant vitamins and trace } \\
\text { minerals, specifically including selenium, should } \\
\text { be provided to all critically ill patients receiving } \\
\text { specialised nutrition therapy. }\end{array}$ & $\begin{array}{l}\text { All PN prescriptions should include a daily dose of } \\
\text { multivitamins and trace elements. }\end{array}$ \\
\hline $\begin{array}{l}\text { Insufficient data to make a recommendation } \\
\text { regarding IV/PN zinc supplementation in critically } \\
\text { ill patients. }\end{array}$ & (Grade B recommendation) & (Grade C recommendation) \\
\hline $\begin{array}{l}\text { Insufficient data to make a recommendation } \\
\text { regarding IV/PN selenium supplementation alone, or } \\
\text { in combination with other antioxidants, in critically } \\
\text { ill patients. }\end{array}$ & & RDAls and trace elements. \\
\hline
\end{tabular}

ASPEN: American Society for Parenteral and Enteral Nutrition, CCCPG: Canadian Critical Care Practice Guidelines, ESPEN: European Society for Clinical Nutrition and Metabolism, IV: intravenous, PN: parenteral nutrition, RDA: recommended dietary allowance, SCCM: Society of Critical Care Medicine

Se, and $574 \mu \mathrm{mol}$ Zn per day (IV) demonstrated a significantly improved clinical course, including better graft take and fewer infectious complications. Supplementation was again associated with a significant reduction in infectious complications, especially bronchopneumonia. ${ }^{107}$

A growing body of evidence is emerging that demonstrates the potential benefits of micronutrient and specifically antioxidant

Table V: Approximate ICU costs per day*

\begin{tabular}{|c|c|c|c|}
\hline \multicolumn{4}{|c|}{ A. Standard high care postoperative costs (12 hours) } \\
\hline High care bed (R7 000.00/day) & & & 3500.00 \\
\hline Enoxaparin & $40 \mathrm{mg} \mathrm{SC}$ & $x 1$ & 76.80 \\
\hline Morphine & $15 \mathrm{~g}$ & 5 amps & 23.96 \\
\hline Metoclopramide & $10 \mathrm{mg}$ & $1 \mathrm{amp}$ & 2.50 \\
\hline Paracetamol & $1 \mathrm{~g}$ & 2 amps & 130.00 \\
\hline Cefazolin & $1 \mathrm{~g}$ & $2 \mathrm{amps}$ & 25.60 \\
\hline TOTAL (High care bed and medication) & & & R3 758.86 \\
\hline \multicolumn{4}{|c|}{ B. ICU costs and medication (treatment of complication) } \\
\hline ICU bed only, excludes ventilation & & & 10000.00 \\
\hline Phenylephrine & $(10 \mathrm{mg} / \mathrm{ml}) 1 \mathrm{ml}$ & $\times 30$ & 1807.00 \\
\hline Enoxaparin & $40 \mathrm{mg} \mathrm{SC}$ & $x 1$ & 76.80 \\
\hline Esomeprazole & $40 \mathrm{mg} \mathrm{IV}$ & $x 1$ & 186.57 \\
\hline Caspofungin & $50 \mathrm{mg} \mathrm{IV}$ & $x 1$ & 2401.22 \\
\hline Imipenem-cilastatin & $500 \mathrm{mg}$ IV & $x 8$ & 1982.05 \\
\hline Linezolid & $600 \mathrm{mg}$ IV & $x 2$ & 997.92 \\
\hline Amiodarone & $200 \mathrm{mg} \mathrm{NGT}$ & $\times 3$ & 51.63 \\
\hline Morphine & $15 \mathrm{~g}$ & 10 amps & 47.93 \\
\hline Metoclopramide & $10 \mathrm{mg}$ & $3 \mathrm{amps}$ & 7.50 \\
\hline Remifentanil & $5 \mathrm{mg}$ & $\times 5$ & 2508.00 \\
\hline TOTAL (ICU bed and medication) & & & R20 066.62 \\
\hline \multicolumn{4}{|l|}{ C. Enteral nutrition + IV glutamine } \\
\hline Semielemental feed & 2 litres & $x 1$ & 511.64 \\
\hline IV glutamine & $200 \mathrm{ml}$ & $x 1$ & 738.81 \\
\hline TOTAL (Enteral nutrition + IV glutamine) & & & R1 250.45 \\
\hline
\end{tabular}

* These are approximate costs in one setting (Gauteng private hospital; 2012) used as an example only (R20 $066.62 \times 3$ days $=$ R60 199.86) micronutrient supplementation in critically ill patients. A recent systematic review included 15 RCTs involving 1714 participants (primary objectives) and 18 RCTs involving 1849 participants (secondary objectives). ${ }^{100}$ This updated review concluded and supported previous findings ${ }^{108}$ that micronutrient supplementation in the critically ill may be associated with a decrease in overall mortality [RR $0.78,95 \% \mathrm{Cl} 0.67-0.90, \mathrm{I}^{2}=0 \%, \mathrm{p}$-value $=0.0009$ ] and more specifically in 28-day mortality (RR 0.75 , $95 \% \mathrm{Cl} 0.63-0.88, \mathrm{I}^{2}=0 \%, \mathrm{p}$-value $\left.=0.0006\right)$. Micronutrient supplementation in this updated review was not associated with a decrease in infectious complications, similar to the findings of Heyland et al. ${ }^{108}$ This finding could possibly indicate that the observed mortality effect was mediated by other mechanisms, e.g. increased organ function. The updated review was the first to report on LICU and length of stay and concluded that these outcomes were unaffected by micronutrient supplementation. A sensitivity analysis of combined micronutrient supplementation indicated a significant reduction in mortality (RR 0.69 , 95\% $\mathrm{Cl} 0.54-0.90, \mathrm{I}^{2}=2 \%, \mathrm{p}$-value $=0.006$ ). Although in contrast to the findings of the previous systematic review $^{108}$ (i.e. single nutrients were associated with a significant decrease in mortality, combined micronutrients were not), this new finding of the updated review supports prior hypotheses and the rationale underlying the use of combinations of micronutrients, namely the biochemical properties of the endogenous antioxidant network and micronutrients' interdependence for regeneration of antioxidant defenses. ${ }^{109}$ This updated systematic review did not find clear evidence that PN was superior to EN administration in terms of clinical outcomes. The authors recommended that future studies could investigate the use of PN and EN administration of micronutrients to maximise the opportunity of demonstrating a treatment effect, if 
one really exists. The secondary outcomes of this review confirmed that timing, duration and dosing are key factors to ensure optimal clinical benefit. ${ }^{100}$

The latest systematic review, including 21 trials, regarding antioxidant micronutrients in the critically ill confirm the mortality, length of stay and LICU findings by Visser et al, ${ }^{100}$ and additionally report a significant reduction in duration of mechanical ventilation (WMD in days $=-0.67,95 \% \mathrm{Cl}-1.22$ to $-0.13, \mathrm{p}$-value $=0.02$ ) with antioxidant supplementation. ${ }^{110}$ Furthermore, antioxidants were associated with a significant reduction in overall mortality in patients with higher risk of death (> 10\% mortality in control group) (RR $0.79,95 \% \mathrm{Cl} 0.68-0.92$, $\mathrm{p}$-value $=0.003$ ), whereas no significant effect was observed for trials of patients with a lower mortality in the control group. ${ }^{110}$

The Cochrane Database Systematic Review by Avenell et al (updated 2007) investigating the effects of single-nutrient supplementation, specifically selenium supplementation, including the selenium-containing compound ebselen, concluded: "There is limited evidence to recommend supplementation of critically ill patients with selenium or ebselen". 111 They found no significant differences for overall mortality and infectious complications and no clear evidence of the benefits of such supplementation for ventilator days, LICU, length of stay or quality of life. However, they did find that the evidence was more suggestive of a benefit on mortality in the first month for general ICU patients when compared with those with severe pancreatitis ( $p$-value $=0.02$ ). The more recent SIGNET trial ${ }^{58}$ found that $500 \mu \mathrm{g}$ selenium daily as part of PN in critically ill patients significantly decreased new infections in a subset of patients who received the supplement for $\geq 5$ days, but it did not affect mortality. When the SIGNET trial data ${ }^{58}$ for selenium supplementation were entered into the current Cochrane systematic review, ${ }^{111}$ the random effects risk ratio for mortality changed from $0.75\left(0.59-0.96, \mathrm{I}^{2}=0 \%\right)$ to 0.86 $\left(0.74-1, I^{2}=0 \%\right)$, and the risk ratio for new infections changed from $1.22\left(0.67-2.23, \mathrm{I}^{2}=0 \%\right)$ to $0.93\left(0.79-1.09, \mathrm{I}^{2}=0 \%\right){ }^{111}$

In one older study, high-dose vitamin $\mathrm{C}$ administration during resuscitation (66 mg/kg/hour) was shown to attenuate lipid peroxidation and reduce resuscitation fluid requirements, as well as post-burn oedema. The length of mechanical ventilation was also significantly reduced and improved early respiratory function was observed. ${ }^{112}$

Other micronutrients that have received attention in recent years include vitamin $D$ and vitamin $B_{12}$. Vitamin $D$ deficiency states have been described in patients with severe sepsis and other critically ill populations ${ }^{113,114}$ with low levels of vitamin D-binding hormone being reported. ${ }^{115}$ Studies of vitamin $D$ replacement studies in the critically ill have mainly considered short-term outcomes and have generally led to increases in vitamin D levels. ${ }^{116,117}$ Whether the latter translates into meaningful clinical outcomes remain to be seen. It is unclear whether low levels of vitamin D contribute to critical 
illness or are just a marker of illness severity. The outcomes of large clinical trials that investigated vitamin D supplementation are currently awaited. It is proposed that future studies should examine vitamin $D$ as well as important metabolites of vitamin $D$, their binding proteins and parathyroid axis. The potential benefit of IV vitamin $B_{12}$ supplementation as a pharmaconutrient in critically ill patients has been described, ${ }^{118}$ but clinical intervention trials studying vitamin $B_{12}$ as a pharmaconutrient strategy in the critical care setting are awaited. One recent observational study indicated an increased mortality rate in patients with Vitamin $B_{12}$ levels over $900 \mathrm{pg} / \mathrm{ml}$ ( $p$-value < 0.0002). ${ }^{119}$ Nutrition therapy practitioners should always bear in mind that "much more is not necessarily better" and that some micronutrients have or may have a narrow therapeutic window when high-dose supplementation is being considered. Furthermore, in this group of patients the potential exists for the creation of a prooxidant microenvironment with deleterious patient outcomes. This should always be borne in mind.

Establishing exact micronutrient requirements in the critically ill has proven to be notoriously difficult. Various general sets of guidelines are available (Table IV). Despite these guidelines, little consensus exists as to what to use when, and many questions remain regarding required doses, routes and timing of replacements or supplementation.

Providing micronutrients to include the full range of trace elements and vitamins is an integral part of nutritional support. In practical terms in the South African context, it is clear that micronutrients should be provided at least at the current available recommended doses to prevent overt clinical deficiencies. For other claims, indications and higher doses, the literature consistently indicates that the ratio of risk (adverse effects) to benefit (mortality) may be favourable, and if such higher doses are used in practice, it should be within the dose range that the current experience covers, and for the clinical settings studied only.

Finally, the bigger picture should always be considered, bearing in mind the complexity of the acute phase response and the vast heterogeneity of the critical care population. Optimal nutrition therapy includes all relevant components, including attention to energy, protein, carbohydrates, lipids, fluids, fibre and the discussed immunonutrients and pharmaconutrients, in the right mix, at the right time, to the right patients, to ensure optimal clinical benefit and outcome.

\section{Cost considerations}

Considering the evidence base, sets of guidelines are available for the implementation of immunonutrition and pharmaconutrition in appropriate circumstances. But often, and specifically also in the South African setting, the final verdict regarding implementation is determined by cost. The available evidence on the benefits of and cost containment by nutrition therapy should not only be seen within the context of the limitations of the studies being reported and the regional variation of costs, but also within the context of the consistency of the reported benefits.
Basic nutrition therapy costs have been reported to be US\$2040 per day (EN nutrition), while PN nutrition costs US\$55-200 per day. In addition, antibiotic therapy has been reported to amount to approximately US\$65-US\$1 345/day. ${ }^{120}$

Already in 1997, it was shown that an immune-enhancing formula containing arginine not only significantly reduced late postoperative events in patients undergoing gastric surgery, but also reduced the costs of treating complications (83 563 Deutsche Mark in the experimental diet group vs. 122430 Deutsche Mark in the control group, resulting in a cost-reduction of 38867 Deutsche Mark). ${ }^{121}$ In a more recent study, the projected investment and cost savings using arginine-containing formula for 1000 well-nourished surgery patients, with a $20 \%$ base infection rate, was US $\$ 45000$ and US\$1 442000 respectively. The projected investment and cost savings using arginine-containing formula for 200 malnourished surgical patients, with a $20 \%$ base infection rate, was US $\$ 44000$ and US\$272 400 respectively. Finally, the projected investment and cost savings using arginine-containing formula for 200 trauma patients, with a $60 \%$ base infection rate, was US\$35 000 and US\$759 400 respectively. ${ }^{122}$

Recently, a simulation study, incorporating outcome rates from 200 Italian ICUs for over 60000 patients, was conducted to determine whether PN alanyl-glutamine supplementation (compared to standard TPN) in critically ill patients had the potential to partially or totally offset its own costs by reducing the consumption of other medical resources. The glutamine-supplemented TPN resulted in a reduced mortality rate $(26.4 \pm 1.6 \%$ vs. $34.5 \pm 2.1 \%)$, reduced infection rate $(13.8 \pm 2.9$ vs. $18.8 \pm 3.9 \%)$ and reduced hospital length of stay ( $24.9 \pm 0.3$ days vs. $26.0 \pm 0.3$ days). More importantly in this context, it resulted in a lower total cost per patient ( $€ 23409$ $\pm € 3345$ vs. $€ 24161 \pm € 3523$ ). The treatment cost was completely offset by savings on ICU and antibiotic costs. ${ }^{123}$

A comparison of conventional vs. preoperative immunonutrition in gastrointestinal cancer patients resulted in a total nutrition cost of $€ 3407$ in the conventional group and $€ 14729$ in the supplemented or preoperative group. In patients without complications, the inhospital routine care was similar, but the mean cost of complication per patient in the conventional group was $€ 6178$, compared to $€ 4639$ in the preoperative group ( $p$-value $=0.05$ ). The total cost of patients with complications was $€ 535236$ in the conventional group and $€ 334148$ in the preoperative group. Cost-effectiveness (analysis performed by dividing per-patient costs of clinical nutrition and costs of treating postoperative complications with the percentage of complication-free patients; thus, the cost of achieving one complication-free patient per group) was $€ 6245$ in the conventional group and €2 985 in the supplemented group. ${ }^{124}$

To the authors' knowledge, there are no comparative cost data in South Africa. A simple approximate cost calculation rather than an economic analysis, (only including ICU bed and medication but excluding the cost of ventilator support, IV fluids and medical and allied professional fees) was undertaken (as an example) to determine the cost of one day for a high care (no complications), a critically ill patient in the ICU (with complications) as well as the 
approximate cost of one day of enteral feeding with a semielemental formula plus $200 \mathrm{ml}$ IV glutamine (Gauteng private hospital setting protocols and costs) (Table V). The costs were calculated for an elderly, well-nourished patient, who had a knee replacement and developed complications (sepsis and atrial fibrillation; treated with second- and third- generation antibiotics and an antifungal agent), who needed ventilation. Standard costs, if the patient did not develop complications for 12 hours in a high care unit (standard protocol) would have been R3 758.86 (Table V, Section A). In this example and in comparative terms, the standard (semielemental) feed as well as specialised (glutamine) nutrition therapy, alone or in combination (Table V, Section C), can be seen as relatively "minor" compared to the costs, in the same patient, of medication necessitated by the complication described in the example (Table V, Section B). If the assumption was also to be made that preventive nutrition support/ therapy would have significantly reduced the risk of the complication that was encountered for a total costs of R5 009.31 (Table V, Sections $A$ and $C$ ), the approach would have still achieved significant costs containment in comparison to the costs of treating the specific complications in the example used.

Bearing in mind that some studies have indicated that LICU can be shortened by two to three days with IV glutamine, when needed, the authors compared the cost of seven days of IV glutamine ( $738.81 \times 7=$ R5 171.67) vs. three extra ICU days ( 20066.62 x $3=$ R60 199.86) in order to highlight the cost containment a pharmaconutrient-based nutrition therapy approach has to offer in the appropriate setting (the authors concede the theoretical nature of the example and the assumptions made therein).

Amid a growing and strengthening evidence base supporting benefit, and clear indications of outcome benefits, as well as potential cost savings, critical care nutrition guidelines have been developed to help busy practitioners decide how to feed their critically ill patients. Despite good adherence to some recommendations, large gaps exist between many current recommendations and actual practice in ICUs, and consequently, nutrition therapy is still suboptimal. ${ }^{125}$ Knowledge-to-action models need to be explored and implemented to optimise nutrition therapy at the bedside. ${ }^{126}$

\section{Conclusion}

The value of immunonutrition formula in the management of critically ill and preoperative and postoperative patients is now acknowledged by many nutrition therapy and medical practitioners. Amid the demonstration of clear clinical and cost-containment benefit in defined conditions, South African practitioners should also aim to close the knowledge-to-best-practice gap to optimise nutrition therapy and ultimately, clinical outcome in critically ill patients. It is clear that continued clinical research is necessary for an even better understanding of immunonutrition and pharmaconutrition approaches. Specifically, large, multi-centre, prospective RCTs that evaluate each immune-modulating nutrient individually, as 
well as in various combinations, at various doses, and in defined patient populations, would lead to better evidence-based practice guidelines. ${ }^{127} \mathrm{~A}$ few such trials are already underway. In future, a paradigm shift to pharmaconutrition is gaining momentum, a practice which dissociates the administration of key single nutrients in the form of requirement-based PN or EN nutrition from the delivery of pharmaconutrients in the full effective pharmacological dose, as evaluated in large, well designed trials, in order to achieve therapeutic effects. ${ }^{1}$ The current use of clinical pharmacology, molecular biology and clinical research principles in the study of pharmaconutrients should provide further answers on how to administer the right nutrients, in the right doses, at the right time, in critically ill patients. ${ }^{2}$

\section{References}

1. Jones NE, Heyland DK. Pharmaconutrition: a new emerging paradigm. Curr Opin Gastroenterol. 2008;24(2):215-222.

2. Wischmeyer P. Nutritional pharmacology in surgery and critical care: "you must unlearn what you have learned". Curr Opin Anesthesiol. 2011;24:381-388.

3. Calder PC. Lipids and the critically ill patient. Nestle Nutr Workshop Ser Clin Perform Programme. 2003;8:75-91; discussion 91-8.

4. Grimble RF. Nutritional modulation of immune function. Proc Nutr Soc. 2001;60(3):389-397.

5. Dupertuis YM, Meguid MM, Pichard C. Advancing from immunonutrition to a pharmaconutrition: a gigantic challenge. Curr Opin Clin Nutr Metab Care. 2009;12(4):398-403.

6. Ochoa JB. Separating pharmaconutrition from classic nutrition goals: a necessary step. Crit Care Med. 2008:36(1):347-348.

7. Satyaraj E. Emerging Paradigms in Immunonutrition. Top Companion Anim Med. 2011;26(1):25-32

8. Mizock BA. Immunonutrition and critical illness: An update. Nutrition. 2010;26:701-707.

9. Gottschlich MM, Jenkins M, Warden GD, Baumer T, Havens P, Snook JT, et al. Differential effects of three enteral dietary regimens on selected outcome variables in burn patients. J Parent En Nutr. 1990;14:225-236.

10. Aller MA, Arias Jl, Alonso-Poza A, Arias J. A review of metabolic staging in severely injured patients. Scand J Trauma Resusc Emerg Med. 2010;18:27.

11. Kruizenga HM, Van Tulder MW, Seidell JC, Thijs A, Ader HJ, Van Bokhorst-de van der Schueren MA. Effectiveness and cost-effectiveness of early screening and treatment of malnourished patients. Am J Clin Nutr. 2005;8:1082-1089.

12. Feldblum I, German L, Castel H, Harman-Boehm I, Bilenko N, Eisinger M, et al. Characteristics of undernourished older medical patients and the identification of predictors for undernutrition status. Nutr J. 2007;6:37.

13. Barr J, Hecht M, Flavin KE, Khorana A, Gould MK. Outcomes in critically ill patients before and after the implementation of an evidence-based nutritional management protocol. Chest 2004;125(4):1446-1457

14. Lim SH, Lee JS, Chae SH, Ahn BS, Chang DJ, Shin CS. Prealbumin is not sensitive indicator of nutrition and prognosis in critical ill patients. Yonsei Med J. 2005:46(1):21-26.

15. Holmes S. The effects of undernutrition in hospitalised patients. Nurs Stand 2007:44:22(12):35-38

16. Neelemaat F, Kruizenga HM, De Vet HCW, Seidell JC, Butterman M, Van Bokhorst-van de Schueren MAE. Screening malnutrition in hospital outpatients. Can the SNAQ malnutrition screening tool be applied to this population. Clin Nutr. 2008;27:439-446.

17. Kondrup J, Allison SP, Elia M, Vellas B, Plauth M; Educational and Clinical Practice Committee, European Society of Parenteral and Enteral Nutrition (ESPEN). ESPEN guidelines for nutritional screening 2002. Clin Nutr. 2003;22(4):415-421.

18. Kyle UG, Genton L, Pichard C. Hospital length of stay and nutritional status. Curr Opin Clin Nutr Metab Care. 2005;8(4):397-402.

19. Ozkalkanli MY, Ozakalkanli DT, Katircioglu K, Savaci S. Comparison of tools for nutrition assessment and screening for predicting the development of complications in orthopedic surgery. Nutr Clin Pract. 2009;24(2):274-280.

20. Marik PE, Flemmer M. Immunonutrition in the surgical patient. Minerva Anestesiol. 2012; 78(3):336-342.

21. Mudge AM, Kasper K, Clair A, Redfern H, Bell JJ, Barras MA, Dip G, Pachana NA. Recurrent readmissions in medical patients: a prospective study. J Hosp Med. 2011;6(2):61-67.

22. Reilly JJ Jr, Hull SF, Albert N, Waller A, Bringardener S. Economic impact of malnutrition: a model system for hospitalized patients. J Parenter Enteral Nutr. 1988;12(4):371-376.

23. Chima CS, Barco K, Dewitt MLA, Maeda M, Teran JC, Mullen KD: Relationship of nutritiona status to length of stay, hospital costs, discharge status of patients hospitalized in the medicine service. J Am Diet Assoc. 1997;97:975-978.
24. Desport JC, Preux PM, Truong TC, Vallat JM, Sautereau D, Couratier P. Nutritional status is a prognostic factor for survival in ALS patients. Neurology. 1999;53(5):1059-1073.

25. Braunschweig C, Gomez S \& Sheean PM. Impact of declines in nutritional status on outcomes in adult patients hospitalized for more than 7 days. J Am Diet Assoc. 2000; 100:1316-1322.

26. O'Flynn J, Peake H, Hickson M, Foster D, Frost G. The prevalence of malnutrition in hospitals can be reduced: Results from three consecutive cross-sectional studies. Clin Nutr. 2005;24:1078-1088.

27. Löser C. Malnutrition in Hospital. The Clinical and Economic Implications. Dtsch Arztebl Int. 2010;107(51-52):911-917.

28. Sorensen J, Kondrup J, Prokopowicz J, Schiesser M, Krähenbühl L, Meier R, Liberda M; Euro00PS study group. Euro00PS: an international, multicentre study to implement nutritional risk screening and evaluate clinical outcome. Clin Nutr. 2008;27(3):340-249.

29. Álvarez-Hernández J, Planas Vila M, León-Sanz M, García de Lorenzo A, Celaya-Pérez S García-Lorda P, Araujo K, Sarto Guerri B; on behalf of the PREDyCES $\otimes$ researchers. Prevalence and costs of malnutrition in hospitalized patients; the PREDyCES® Study. Nutr Hosp. 2012;27(4):1049-1059.

30. O'Keefe SJ. Malnutrition among adult hospitalised patients in Zululand during the drought of 1983. S Afr Med J. 1983;64(16):628-629.

31. O'Keefe SJ, Thusi D, Epstein S. The fat and the thin-a survey of nutritional status and disease patterns among urbanized Black South Africans. S Afr Med J. 1983;63(18):679-683.

32. O'Keefe SJ, Dicker J, Delport I. Incidence of malnutrition in adult patients in Groote Schuur Hospital. S Afr Med J. 1986;70(1):16-20

33. Symmonds KL. Nutritional status of hospitalised adult patients with pulmonary tuberculosis. S Afr J Clin Nutr. 1991;4(1):17-20

34. Grobler-Barnard D, Labadarios D, Walelle AA, et al. The nutritional status of patients at Tygerberg Hospital. S Afr Med J. 1997;87:1238.

35. Kingu HJ, Longo-Mbenza B, Dhaffala A, Mazwai EL. Survival function and protein malnutrition in burns patients at a rural hospital in Africa. World J Surg. 2011;35(7):1546-1552

36. Burke J. Infection control - A problem for patient safety. N Engl J Med. 2003;348:651-656.

37. Martin GS, Mannino DM, Eaton SE, Moss M. The epidemiology of sepsis in the United States from 1979 through 2000. N Engl J Med. 2003;348:1546-1554.

38. Balk RA. Severe sepsis and septic shock. Definitions, epidemiology, and clinical manifestations. Crit Care Clin. 2000;16(2):179-192

39. Xu J, Yunshi Z, Li R. Immunonutrition in surgical patients. Curr Drug Targets. 2009;10:771-777.

40. Mannick JA, Rodrick ML, Lederer JA. The immunologic response to injury. J Am Coll Surg 2001:193(3): 237-244

41. Hietbrink F, Koenderman L, Rijkers GT, Leenen LPH. Trauma: the role of the innate immune system. World J Emerg Surg. 2006;1:15

42. Murphy TJ, Paterson HM, Mannick JA, Lederer JA. Injury, sepsis, and the regulation of toll-like receptor responses. J Leukoc Biol. 2004;75:400-407.

43. Elia M. The economics of malnutrition. Nestle Nutr Workshop Ser Clin Perform Programme. 2009;12:29-40

44. Drover JW, Cahill NE, Kutsogiannis J, Pagliarello G. Wischmeyer P, Wang M, Day AG, Heyland DK. Nutrition therapy for the critically ill surgical patient: we need to do better! J Parenter Enteral Nutr. 2010;34(6):644-652

45. Sauerwein HP. Emerging science in whey protein. Clinical Nutrition Highlights. 2005;1:2-7.

46. Khoshoo V, Brown S. Gastric emptying of two whey-based formulas of different energy density and its clinical implication in children with volume intolerance. Eur J Clin Nutr. 2002;56:656-658.

47. Lawson CM, Miller KR, Smith VL, McClave SA. Appropriate protein and specific amino acid delivery can improve patient outcome: Fact or fantasy? Curr Gastroenterol Rep. 2011;13:380-387.

48. De Aguilar-Nascimento JE, Prado Silveira BR, Dock-Nascimento DB. Early entera nutrition with whey protein or casein in elderly patients with acute ischemic stroke: a doubleblind randomized trial. Curr Opin Clin Nutr Metab Care. 2003;6(2):217-222

49. Lacey JM, Wilmore DW. Is glutamine a conditionally essential amino acid? Nutr Rev 1990;48:297-309.

50. Wischmeyer PE. Glutamine: role in critical illness and ongoing clinical trials. Curr Opin Gastroenterol. 2008;24:190-197.

51. Windle EM. Glutamine supplementation in critical illness: evidence, recommendations, and implications for clinical practice in burn care. J Burn Care Res. 2006;27:764-772

52. Curi R, Newsholme P, Procopio J, Lagranha C, Gorjão R, Pithon-Curi TC. Glutamine, gene expression, and cell function. Front Biosci. 2007;12:344-357.

53. McClave SA, Martindale RG, Vanek VW, McCarthy M, Roberts P, Taylor B, et al. Guidelines for the provision and assessment of nutrition support therapy in the adult critically ill patient: Society of Critical Care Medicine (SCCM) and American Society for Parenteral and Enteral Nutrition (A.S.P.E.N.). J Parenter Enteral Nutr. 2009;33(3):277-316

54. Singer P, Berger MM, Van den Berghe G, Biolo G, Calder P, Forbes A, et al. ESPEN guidelines on Parenteral Nutrition: Intensive care. Clin Nutr. 2009;28:387-400.

55. Heyland DK, Dhaliwal R, Drover JW, Gramlich L, Dodek P; Canadian Critical Care Clinica Practice Guidelines Committee. Canadian clinical practice guidelines for nutrition support in 
mechanically ventilated, critically ill adult patients. J Parenter Enteral Nutr. 2003; 27(5):355-373.

56. Critical Care Nutrition. Canadian clinical practice guidelines; http://www.criticalcarenutrition com/ (Practice Guidelines). [Accessed 1 August 2012.]

57. Wernerman J, Kirketeig T, Andersson B, Berthelson H, Ersson A, Friberg H, et al. Scandinavian glutamine trial: A pragmatic clinical multi-centre RCT of ICU patients. Acta Anaesth Scand. 2011;55(7):812-818.

58. Andrews PJ, Avenell A, Noble DW, Campbell MK, Croal BL, Simpson WG, Vale LD, Battison CG, Jenkinson DJ, Cook JA; Scottish Intensive care Glutamine or seleNium Evaluative Trial Trials Group. Randomised trial of glutamine, selenium, or both, to supplement parenteral nutrition for critically ill patients. BMJ. 2011;342:d1542.

59. Wischmeyer PE. Malnutrition in the acutely ill patient: is it more than just protein and energy? S Afr J Clin Nutr. 2011;24(3)Suppl:S1-S7.

60. Eroglu A. The effect of intravenous alanyl-glutamine supplementation on plasma glutathione levels in intensive care unit trauma patients receiving enteral nutrition: the results of a randomized controlled trial. Anesth Analg. 2009;109(2):502-505.

61. Pérez-Bárcena J, Crespi C, Regueiro V, Marsé P, Raurich JM, Ibáñez J, et al. Lack of effect of glutamine administration to boost the innate immune system response in trauma patients in the intensive care unit. Crit Care. 2010;14(6):R233.

62. Garrel D, Patenaude J, Nedelec B, Samson L, Dorais J, Champoux J, et al. Decreased mortality and infectious morbidity in adult burn patients given enteral glutamine supplements: a prospective, controlled, randomized clinical trial. Crit Care Med. 2003;31(10):2444-2449.

63. Peng $X$, Hong Y, You Z, Wang P, Wang S. Glutamine granule-supplemented enteral nutrition maintains immunological function in severely burned patients. Burns. 2006;32:589-593.

64. Peng X, Hong Y, You Z, Wang P, Wang S. Clinical and protein metabolic efficacy of glutamine granules-supplemented enteral nutrition in severely burned patients. Burns. 2005;31:342-246

65. Soguel L, Chioléro RL, Ruffieux C, Berger MM. Monitoring the clinical introduction of a glutamine and antioxidant solution in critically ill trauma and burn patients. Nutrition. 2008;24(11-12):1123-1132.

66. Heyland DK, Dhaliwal R, Day AG, Muscedere J, Drover J, Suchner U, Cook D; Canadian Critica Care Trials Group. REducing Deaths due to OXidative Stress (The REDOXS Study): Rationale and study design for a randomized trial of glutamine and antioxidant supplementation in critically-ill patients. Proc Nutr Soc. 2006;65(3):250-263.

67. Al Balushi RM, Paratz JD, Cohen J, Banks M, Dulhunty J, Roberts JA, Lipman J. Effect of intravenous Glutamine supplementation IN Trauma patients receiving enteral nutrition study protocol (GLINT Study): a prospective, blinded, randomised, placebo-controlled clinical trial. BMJ Open. 2011;1(2):e000334.

68. Critical Care Nutrition. The RE-ENERGIZE Study: RandomizEd Trial of ENtERal Glutamine to minimIZE Thermal Injury. http://www.criticalcarenutrition.com/ (Research). [Accessed 1 August 2012.]

69. Kreymann KG, Berger MM, Deutz NE, Hiesmayr M, Jolliet P, Kazandjiev G, et al. ESPEN guidelines on Enteral Nutrition: Intensive care. Clin Nutr. 2006;25(2):210-223

70. Stechmiller JK, Childress B, Porter T. Arginine immunonutrition in critically ill patients: A clinical dilemma. Am J Crit Care. 2004;13(1):17-23.

71. Witte MB, Thornton FJ, Tantry U, Barbul A. L-Arginine supplementation enhances diabetic wound healing: involvement of the nitric oxide synthase and arginase pathways. Metabolism. 2002:51(10):1269-1273.

72. Heyland DK, Novak F, Drover JW, Jain M, Su X, Suchner U. Should immunonutrition become routine in critically ill patients? A systematic review of the evidence. JAMA. 2001;286(8):944-953

73. Dent $\mathrm{D}$, Heyland $\mathrm{D}$, Levy H. Immunonutrition may increase mortality in critically ill patients with pneumonia: results of a randomized trial (abstract). Crit Care Med. 2003;30:A17.

74. Bertolini G, Lapichino G, Radrizzani D, Facchini R, Simini B, Bruzzone P, et al. Early enteral immunonutrition in patients with severe sepsis: results of an interim analysis of a randomized multicentre clinical trial. Intensive Care Med 2003:29(5):834-840.

75. Bower RH, Cerra FB, Bershadsky B, Licari JJ, Hoyt DB, Jensen GL, et al. Early enteral administration of a formula (Impact) supplemented with arginine, nucleotides, and fish oil in intensive care unit patients: results of a multicenter, prospective, randomized, clinical trial. Crit Care Med. 1995;23(3):436-449.

76. Ochoa JB, Udekwu A0, Billiar TR, Curran RD, Cerra FB, Simmons RL, et al. Nitrogen oxide levels in patients after trauma and during sepsis. Ann Surg. 1991;214(5):621-626.

77. Bansal V, Ochoa JB. Arginine availability, arginase, and the immune response. Curr Opin Clin Nutr Metab Care. 2003:6(2):223-228.

78. Popovic PJ, Zeh HJ, Ochoa JB. Arginine and Immunity. J Nutr. 2007;137(6 Suppl 2):1681S-1686S

79. Drover JW, Dhaliwal R, Weitzel L, Wischmeyer PE, Ochoa JB, Heyland DK. Perioperative use of arginine-supplemented diets: a systematic review of the evidence. J Am Coll Surg. 2011;212(3):385-399

80. Cerantola Y, Hübner M, Grass F, Demartines N, Schäfer M. Immunonutrition in gastrointestinal surgery. Br J Surg. 2011;98(1):37-48.

81. Santora R, Kozar RA. Molecular mechanisms of pharmaconutrients. J Surg Res. 2010; 161(2):288-294
82. Aldridge C, Razzak A, Babcock TA, Helton WS, Espat NJ. Lipopolysaccharide-stimulated RAW 264.7 macrophage inducible nitric oxide synthase and nitric oxide production is decreased by an omega-3 fatty acid lipid emulsion. J Surg Res. 2008;149(2):296-302.

83. Pontes-Arruda A, Aragão AM, Albuquerque JD. Effects of enteral feeding with eicosapentaenoic acid, gamma-linolenic acid, and antioxidants in mechanically ventilated patients with severe sepsis and septic shock. Crit Care Med. 2006;34(9):2325-2333.

84. Gadek JE, DeMichele SJ, Karlstad MD, Pacht ER, Donahoe M, Albertson TE, et al: Effect of enteral feeding with eicosapentaenoic acid, gamma-linolenic acid, and antioxidants in patients with acute respiratory distress syndrome. Crit Care Med. 1999;27(8):1409-1420.

85. Singer $\mathrm{P}$, Theilla M, Fisher H, Gibstein L, Grozovski E, Cohen J. Benefit of an enteral diet enriched with eicosapentaenoic acid and gamma-linolenic acid in ventilated patients with acute lung injury. Crit Care Med. 2006;34(4):1033-1038.

86. Pontes-Arruda A, Martins LF, de Lima SM, Isola AM, Toledo D, Rezende E, et al. Enteral nutrition with eicosapentaenoic acid, gamma-linolenic acid and antioxidants in the early treatment of sepsis: results from a multicenter, prospective, randomized, double-blinded, controlled study: the INTERSEPT study. Crit Care. 2011;15(3):R144

87. Grau-Carmona T, Moran-Garcia V, Garcia-de-Lorenzo A, Heras-de-la-Calle G, Quesada-Bellve B, Lopez-Martinez J, et al. Effect of an enteral diet enriched with eicosapentaenoic acid gamma-linolenic acid and anti-oxidants on the outcome of mechanically ventilated, critically ill, septic patients. Clin Nutr. 2011;30(5):578-584

88. Rice TW, Wheeler AP, Thompson BT, deBoisblanc BP, Steingrub J, Rock P; NHLBI ARDS Clinical Trials Network. Enteral omega-3 fatty acid, gamma-linolenic acid, and antioxidant supplementation in acute lung injury. JAMA. 2011;306(14):1574-81.

89. Stapleton RD, Martin TR, Weiss NS, Crowley JJ, Gundel SJ, Nathens AB, et al. A phase randomized placebo-controlled trial of omega- 3 fatty acids for the treatment of acute lung injury. Crit Care Med. 2011. 39(7):1655-62.

90. Barbosa VM, Miles EA, Calhau C, Lafuente E, Calder PC. Effects of a fish oil containing lipid emulsion on plasma phospholipid fatty acids, inflammatory markers, and clinical outcomes in septic patients: a randomized, controlled clinical trial. Crit Care. 2010;14(1):R5

91. Wang X, Li W, Zhang F, Pan L, Li N, Li J. Fish oil-supplemented parenteral nutrition in severe acute pancreatitis patients and effects on immune function and infectious risk: a randomized controlled trial. Inflammation. 2009:32(5):304-309.

92. Khor BS, Liaw SJ, Shih HC, Wang LS. Randomized, double blind, placebo-controlled trial of fish-oil-based lipid emulsion infusion for treatment of critically ill patients with severe sepsis. Asian J Surg. 2011;34(1):1-10

93. Gupta A, Govil D, Bhatnagar S, Gupta S, Goyal J, Patel S, Baweja H. Efficacy and safety of parenteral omega 3 fatty acids in ventilated patients with acute lung injury. Indian J Crit Care Med. 2011;15(2):108-113.

94. Sabater J, Masclans JR, Sacanell J, Chacon P, Sabin P \& Planas M. Effects of an omega-3 fatty acid-enriched lipid emulsion on eicosanoid synthesis in acute respiratory distress syndrome (ARDS): A prospective, randomized, double-blind, parallel group study. Nutr Metab. 2011;8(1):22.

95. Klek S, Chambrier C, Singer P, Rubin M, Bowling T, Staun M, et al. Four-week parenteral nutrition using a third generation lipid emulsion (SMOFlipid) - A double-blind, randomised, multicentre study in adults. Clin Nutr. 2012; Jul 11. [Epub ahead of print.]

96. Piper SN, Schade I, Beschmann RB, Maleck WH, Boldt J, Röhm KD. Hepatocellular integrity after parenteral nutrition: comparison of a fish-oil-containing lipid emulsion with an olivesoybean oil-based lipid emulsion. Eur J Anaesthesiol. 2009:26(12):1076-1082.

97. Sungurtekin H, Deirmenci S, Sungurtekin U, Oguz BE, Sabir N, Kaptanoglu B. Comparison of the effects of different intravenous fat emulsions in patients with systemic inflammatory response syndrome and sepsis. Nutr Clin Pract. 2011;26(6):665-671.

98. Xu Z, Li Y, Wang J, Wu B, Li J. Effect of omega-3 polyunsaturated fatty acids to reverse biopsyproven parenteral nutrition-associated liver disease in adults. Clin Nutr. 2012;31(2):217-223.

99. Wei C, Hua J, Bin C, Klassen K. Impact of lipid emulsion containing fish oil on outcomes of surgical patients: systematic review of randomized controlled trials from Europe and Asia. Nutrition. 2010;26(5):474-481.

100. Visser J, Labadarios D, Blaauw R. Micronutrient supplementation for critically ill adults: A systematic review and meta-analysis. Nutrition. 2011;27(7-8):745-758.

101. Berger MM, Cavadini C, Bart A, Mansourian R, Guinchard S, Bartholdi I, et al. Cutaneous zinc and copper losses in burns. Burns. 1992:18(5):373-380.

102. Hunt DR, Lane HW, Beesinger D, Gallagher K, Halligan R, Johnston D, et al. Selenium depletion in burn patients. J Parenter Enteral Nutr. 1984;8(6):695-699.

103. Berger MM, Rothen C, Cavadini C, Chioléro RL. Exudative mineral losses after serious burns: a clue to the alterations of magnesium and phosphate metabolism. Am J Clin Nutr. 1997;65(5):1473-1481.

104. Voruganti VS, Klein GL, Lu HX, Thomas S, Freeland-Graves JH, Herndon DN. Impaired zinc and copper status in children with burn injuries: need to reassess nutritional requirements. Burns. 2005;31(6):711-716.

105. Berger MM, Eggimann P, Heyland DK, Chioléro RL, Revelly JP, Day A, et al. Reduction of nosocomial pneumonia after major burns by trace element supplementation: aggregation of two clinical trials. Crit Care. 2006;10(6):R153. 
106. Berger MM, Spertini F, Shenkin A, Wardle C, Wiesner L, Schindler C, Chioléro RL. Trace element supplementation modulates pulmonary infection rates after major burns: a double-blond, placebo-controlled trial. Am J Clin Nutr. 1998;68(2):365-371.

107. Berger MM, Baines M, Raffoul W, Benathan M, Chioléro RL, Reeves C, et al. Trace element supplementation after major burns modulates antioxidant status and clinical course by way of increased tissue trace element concentrations. Am J Clin Nutr. 2007;85(5):1293-1300.

108. Heyland DK, Dhaliwal R, Suchner U, Berger MM. Antioxidant nutrients: a systematic review of trace elements and vitamins in the critically ill patient. Intensive Care Med. 2005;1(3):327-337.

109. Berger MM, Chioléro RL. Key vitamins and trace elements in the critically ill. Nestle Nutr Workshop Ser Clin Perform Programme. 2003;8:99-117.

110. Manzanares W, Dhaliwal R, Jiang X, Murch L, Heyland DK. Antioxidant micronutrients in the critically ill: a systematic review and meta-analysis. Crit Care. 2012;16(2):R66. [Epub ahead of print.]

111. Avenell A, Noble DW, Barr J, Engelhardt T. Selenium supplementation for critically ill adults. Cochrane Database Syst Rev. 2004;18(4):CD003703.

112. Tanaka H, Matsuda T, Miyagantani Y, Yukioka T, Matsuda M, Shimazaki S. Reduction of resuscitation fluid volumes in severely burned patients using ascorbic acid administration. Arch Surg. 2000;135(3):326-331.

113. Annweiler C, Pochic S, Fantino B, Legrand E, Bataille R, Montero-Odasso M, Beauchet O. Serum vitamin $D$ concentration and short-term mortality among geriatric inpatients in acute care settings. Adv Ther. 2010;27(4):245-249.

114. Lee P, Eisman JA, Center JR. Vitamin D Deficiency in Critically III patients. N Engl J Med. 2009;360(18):1912-1914.

115. Jeng L, Yamshchikov AV, Judd SE, Blumberg HM, Martin GS, Ziegler TR, Tangpricha V. Alterations in vitamin D status and anti-microbial peptide levels in patients in the intensive care unit with sepsis. J TransI Med. 2009;7:28.

116. Mata-Granados JM, Vargas-Vasserot J, Ferreiro-Vera C, Luque de Castro MD, Pavón RG Quesada Gómez JM. Evaluation of vitamin D endocrine system (VDES) status and response to treatment of patients in intensive care units (ICUs) using an on-line SPE-LC-MS/MS method. $J$
Steroid Biochem Mol Biol. 2010;121(1-2):452-455

117. Amrein K, Sourij H, Wagner G, Holl A, Pieber TR, Smolle KH, et al. Short-term effects of highdose oral vitamin D3 in critically ill vitamin D deficient patients: a randomized, double-blind, placebo-controlled pilot study. Crit Care. 2011;15(2):R104.

118. Manzanares W, Hardy G. Vitamin B12: the forgotten micronutrient for critical care. Curr Opin Clin Nutr Metab Care. 2010;13(6):662-668.

119. Sviri S, Khalaila R, Daher S, Bayya A, Linton DM, Stav I, van Heerden PV. Increased Vitamin B12 levels are associated with mortality in critically ill medical patients. Clin Nutr. 2012;31(1):53-59.

120. Berger MM. Analyzing ICU physician and dietitian adherence to nutrition therapy guidelines. $J$ Parenter Enteral Nutr. 2010;34(6):606-607.

121. Senkal M, Mumme A, Eickhoff U, Geier B, Späth G, Wulfert D, et al. Early postoperative enteral immunonutrition: clinical outcome and cost-comparison analysis in surgical patients. Crit Care Med. 1997;25(9):1489-1496.

122. Strickland A, Brogan A, Krauss J, Martindale R, Cresci G. Is the use of specialized nutritional formulations a cost-effective strategy? A national database evaluation. J Parenter Enteral Nutr 2005;29(1 Suppl):S81-S91.

123. Pradelli L, lannazzo S, Zaniolo O, Muscaritoli M, Eandi M. Effectiveness and cost-effectiveness of supplemental glutamine dipeptide in total parenteral nutrition therapy for critically ill patients: a discrete event simulation model based on Italian data. Int $\mathrm{J}$ Technol Assess Health Care. 2012;28(1):22-28.

124. Braga M, Gianotti L. Preoperative immunonutrition: cost-benefit analysis. J Parenter Enteral Nutr. 2005;29(1 Suppl):S57-S61.

125. Cahill NE, Dhaliwal R, Day AG, et al. Nutrition therapy in the critical care setting: What is "best achievable" practice? An international multicenter observational study. Crit Care Med. 2010;38(2):395-401.

126. Heyland DK, Cahill NE, Dhaliwal R. Lost in (knowledge) translation! J Parenter Enteral Nutr. 2010;34(6):610-615.

127. Worthington ML, Cresci G. Immune-modulating formulas: who wins the meta-analysis race? Nutr Clin Pract. 2011;26(6):650-655 